ASTHMA

\title{
Relationship between socioeconomic status and asthma: a longitudinal cohort study
}

\author{
R J Hancox, B J Milne, D R Taylor, J M Greene, J O Cowan, E M Flannery, G P Herbison, \\ C R McLachlan, R Poulton, M R Sears
}

Thorax 2004;59:376-380. doi: 10.1136/thx.2003.010363

See end of article for authors' affiliations .....................

Correspondence to: Dr R J Hancox, Dunedin Multidisciplinary Health and Development Research Unit, Department of Preventive and Social Medicine, Dunedin School of Medicine, University of Otago, PO Box 913 Dunedin, New Zealand; bob.hancox@dmhdru. otago.ac.nz

Received 20 May 2003 Accepted

23 December 2003

\begin{abstract}
Background: There is conflicting information about the relationship between asthma and socioeconomic status, with different studies reporting no, positive, or inverse associations. Most of these studies have been cross sectional in design and have relied on subjective markers of asthma such as symptoms of wheeze. Many have been unable to control adequately for potential confounding factors.

Methods: We report a prospective cohort study of approximately 1000 individuals born in Dunedin, New Zealand in 1972-3. This sample has been assessed regularly throughout childhood and into adulthood, with detailed information collected on asthma symptoms, lung function, airway responsiveness, and atopy. The prevalence of these in relation to measures of socioeconomic status were analysed with and without controls for potential confounding influences including parental history of asthma, smoking, breast feeding, and birth order using cross sectional time series models.

Results: No consistent association was found between childhood or adult socioeconomic status and asthma prevalence, lung function, or airway responsiveness at any age. Having asthma made no difference to educational attainment or socioeconomic status by age 26 . There were trends to increased atopy in children from higher socioeconomic status families consistent with previous reports.

Conclusions: Socioeconomic status in childhood had no significant impact on the prevalence of asthma in this New Zealand born cohort. Generalisation of these results to other societies should be done with caution, but our results suggest that the previously reported associations may be due to confounding.
\end{abstract}

$\mathrm{T}$ he prevalence of asthma in the developed world has increased over recent decades. At least part of this increase is real and not due to changes in diagnostic practices. ${ }^{1-7}$ This increase in genetically stable populations must be due to environmental or lifestyle factors. Since asthma is more common in westernised/wealthy nations, the increases in prevalence within these countries suggest that asthma may be a disease of affluence. ${ }^{8-10}$

Within countries there have been many attempts to relate the prevalence of asthma and atopy to socioeconomic status (SES). Unlike atopy, which is more common in higher SES groups, ${ }^{11}$ the evidence for socioeconomic patterning in asthma is conflicting. ${ }^{12}{ }^{13}$ Studies have found both increased ${ }^{14-16}$ and decreased $^{17-21}$ prevalence of asthma in higher SES groups, while other studies have found no relationship. ${ }^{22-24}$

There may be several explanations for these findings, including the methodology of the studies. The use of symptoms such as wheeze and cough to indicate asthma may be misleading. This may be because of the occurrence of non-asthmatic wheeze and cough (due to bronchitis, for example) or because of differences in reporting of these symptoms between socioeconomic groups. ${ }^{25-29}$ Alternatively, physician diagnosis and treatment of asthma may differ between economic groups leading to either an apparent increase in prevalence in those with better access to care or an apparent increase in asthma severity in those with inadequate treatment. ${ }^{12}$ Finally, it is probable that SES interacts with specific environmental factors to have different effects on asthma prevalence in different populations. For example, less affluent people in the USA have greater exposure to cockroaches and therefore may have more asthma symptoms due to cockroach allergy. ${ }^{30-32}$ House dust mites are more important in other populations and exposure may be greater in higher SES homes. ${ }^{31} 33$
Clouding the issue further, many studies of SES have been cross sectional and most have been restricted to children. We report a longitudinal cohort study from birth to age 26 that recorded both subjective and objective measures of asthma and atopy to examine the relationship between SES and asthma.

\section{METHODS \\ Participants}

The Dunedin Multidisciplinary Health and Development Study is a longitudinal investigation of health and behaviour in a birth cohort. ${ }^{34}$ Study members were born in Dunedin, New Zealand between April 1972 and March 1973. Of these, 1037 children (91\% of eligible births; $52 \%$ male) participated in the first follow up assessment at age 3, constituting the base sample for the remainder of the study. Cohort families represent the full range of SES in the general population of New Zealand and are primarily white of European descent. Follow up assessments occurred at ages 5, 7, 9, 11, 13, 15, 18, 21 , and at age 26 years when we assessed 980 (96\%) of 1019 study members still alive. The study was approved by the Otago ethics committee and written informed consent was obtained at each assessment.

\section{Measurements of socioeconomic status (SES)}

The primary measures of SES used in this study were based on the scale of Elley and Irving. ${ }^{35}$ The scale places each occupation into one of six categories ( $6=$ unskilled labourer, $\mathrm{l}=$ professional) based on the educational levels and income associated with that occupation in data from the latest New Zealand census.

\section{Childhood SES}

Socioeconomic conditions may change during childhood, and rather than take the measurement from a single point at 
birth or early in life, we calculated childhood SES as the average of the higher SES level of either parent, assessed repeatedly from the study member's birth through to age 15 $(n=1031)$. Although homemakers, unemployed, and students are not classified, only six study members could not be assigned an SES category between birth and age 15 . The distribution of SES classifications was $1-1.9=14.3 \%$; $2-2.9=19.9 \% ; 3-3.9=34.8 \% ; 4-4.9=23.2 \% ; 5-6=7.2 \%$.

\section{Adult SES}

To address the issues of whether adult SES has an impact on current asthma, and also whether the experience of asthma during childhood impacts on adult SES, the adult SES score was measured according to the study member's own ElleyIrving category at age $26(\mathrm{n}=934$, the remaining cohort seen at 26 were homemakers, students, or unemployed and were omitted)..$^{35}$

\section{Alternative measures of SES}

Parental income taken as the total income of both parents recorded on two occasions (ages 13 and 15) and expressed as the mean of the totals at these ages $(n=955)$ was used as an alternative measure of childhood SES. The highest level of educational achievement by age $26 \quad(1=$ no qualifications; $2=$ school certificate only (the most basic New Zealand qualification); $3=$ higher level school qualification (e.g. sixth form certificate), or post-school qualification (e.g. trade certificate diploma); $4=$ bachelors degree or higher) was used as an alternative measure of adult SES $(n=980)$.

\section{Outcome measures}

\section{Asthma, wheeze and cough}

At age 9 the accompanying adult (usually mother) answered questions on current wheezing and coughing symptoms and also provided a retrospective history of respiratory symptoms and illnesses since birth. The frequency, severity, trigger factors, and treatment of symptoms were recorded, including whether a diagnosis of asthma had been made. ${ }^{36}$ At age 11 , 13, and 15 questions were asked regarding symptoms since the last assessment. At age 18,21, and 26 a self-administered questionnaire, $^{37}$ to which we added questions from the American Thoracic Society questionnaire, ${ }^{38}$ was completed by the study member before the interviewer administered questionnaire.

Current asthma was defined as diagnosed asthma with symptoms in the previous year. Current wheeze was defined as all reported wheezing, excluding those with only one or two episodes of wheezing each lasting for less than 1 hour in the previous year. Asthma treatment included any bronchodilator, corticosteroid, or cromoglycate medication.

\section{Lung function and airway responsiveness}

Spirometric tests were performed at each assessment from age 9, recording the best of three acceptable forced expiratory manoeuvres without prior bronchodilator (within 6 hours). At 18 and 26 bronchodilator responsiveness was measured by repeating the spirometric tests 10 minutes after nebulised or metered dose salbutamol $(200 \mu \mathrm{g})$ via a large volume spacer. At ages 9, 11, 13, 15, and 21 a methacholine challenge was performed using a modified Chai protocol ${ }^{39}$ as previously described and validated.$^{40}$ Five deep inhalations of methacholine $0.025 \mathrm{mg} / \mathrm{ml}$ were administered through a Hudson Updraft nebuliser and spirometric tests were repeated after 30 seconds and 2 minutes. Provided the forced expiratory volume in 1 second $\left(\mathrm{FEV}_{1}\right)$ fell less than $20 \%$, further methacholine was administered at concentrations of 0.25 , 2.5 and $25 \mathrm{mg} / \mathrm{ml}$. The procedure was stopped when $\mathrm{FEV}_{1}$ fell by $20 \%$, if there were symptoms of concern, or after the final concentration. The provoking concentration causing a $20 \%$ fall in $\mathrm{FEV}_{1}\left(\mathrm{PC}_{20}\right)$ was determined by linear interpolation. A $\mathrm{PC}_{20}$ of $8 \mathrm{mg} / \mathrm{ml}$ or less was regarded as increased airway responsiveness. Study members showing airflow obstruction at baseline $\left(\mathrm{FEV}_{1} / \mathrm{FVC}<75 \%\right.$ at 9 and 11 years or $<70 \%$ at older ages) were not challenged but instead were retested after salbutamol. An increase in the $\mathrm{FEV}_{1}$ of $10 \%$ of baseline or more was regarded as indicating bronchodilator airway responsiveness.

\section{Atopic status}

Skin prick testing was undertaken at age 13 in 714 study members using house dust mite (Dermatophagoides pteronyssinus, Bencard, UK), grass, cat, dog, horse, kapok, wool, Aspergillus fumigatus, Penicillium, and Cladosporum (HollisterStier, USA).$^{41}$ These were repeated at age 21 in 885 study members with the addition of cockroach allergen (HollisterStier, USA). A positive response was defined as a weal diameter $2 \mathrm{~mm}$ greater than the negative control. Serum IgE was measured at ages 11 and 21 in 571 and 786 study members, respectively. ${ }^{42}$ IgE values were log-transformed before analysis to approximate a normal distribution.

\section{Control variables}

\section{Parental asthma}

The adult attending with the study member at age 7 was asked whether the natural mother and father had asthma, hay fever, or allergies. ${ }^{43}$ This information was obtained again from the study member at age 18. Preference was given to the information obtained at age 7 if available.

\section{Cigarette smoking}

Current smoking was defined as smoking daily for at least 1 month of the previous year. Parental smoking during the study member's life was ascertained at ages 9, 11 and 13 from the accompanying parent and used as an indicator of likely exposure to environmental tobacco smoke. Whether the study member's mother had smoked during pregnancy was asked at age 9 .

\section{Breast feeding}

At the age 3 assessment parents were questioned about breast feeding and its duration. Study members were classified according to whether they had been breast fed for longer than 3 weeks. ${ }^{44}$ The accuracy of recall of the duration of breast feeding was validated by comparison of data recorded prospectively by infant healthcare workers. ${ }^{45}$

\section{Birth order}

Birth order was categorised according to whether the study member had no, one, two, or three or more older siblings.

\section{Statistical analysis}

Analyses of the effects of childhood SES were performed

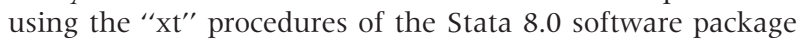
(Stata Corporation, TX) for cross sectional, time series datasets (generalised estimating equations). Continuous variables were analysed using the xt regression model and binary outcomes by the xt logit model. Analyses were undertaken using asthma, atopy, $\mathrm{FEV}_{1} / \mathrm{FVC}$ ratio, and $\log$ IgE levels as dependent variables and childhood SES as the independent variable. All analyses included a term for the age of measurement and were adjusted for sex. Analyses were repeated with adjustment for potential covariates including family history of asthma, smoking, breast feeding, birth order, maternal smoking during pregnancy, and the presence of a smoker in the household. Analyses of the effect of childhood asthma (up to the age of 15) on adult (age 26) SES and of adult SES on adult asthma outcomes were performed 
using linear or logistic regression. p values of $<0.05$ were regarded as statistically significant.

\section{RESULTS}

\section{Childhood SES}

The prevalence of asthma, wheeze, asthma treatment, airway responsiveness, atopy, and the mean $\mathrm{FEV}_{1} / \mathrm{FVC}$ ratio at each age for high, medium, and low Elley-Irving childhood SES groups are shown in fig 1 . These indicate no consistent pattern of association between SES and the asthma outcomes measured. Cross sectional time series analyses also indicate no significant associations between mean childhood SES and a diagnosis of asthma, wheeze, asthma treatment, time off school or work for asthma, lung function, or airway responsiveness to methacholine or salbutamol in either the analyses adjusting for sex alone, or the analyses adjusting for other covariates (table 1).

There was a trend towards increased atopy on skin prick testing (any skin prick test positive) with increasing childhood SES $(p=0.044)$, but this was no longer significant after controlling for birth order, family smoking, smoking during pregnancy, and breast feeding $(\mathrm{p}=0.084)$. There were no significant associations between SES and log serum IgE.

Total parental income at ages 13 and 15 was not associated with current asthma, significant wheeze, asthma treatment, lung function, atopy, serum IgE, or airway responsiveness in either the analyses adjusting for sex alone or the analyses adjusting for other covariates.

\section{Adult SES}

The study member's own SES and educational achievement by age 26 were not significantly associated with current asthma, doctor diagnosed asthma, current wheeze, time off work due to asthma, or bronchodilator response at age 26. Significant associations between being woken by a cough at 26 and both adult SES and educational status in unadjusted analyses were not significant after adjustment for current
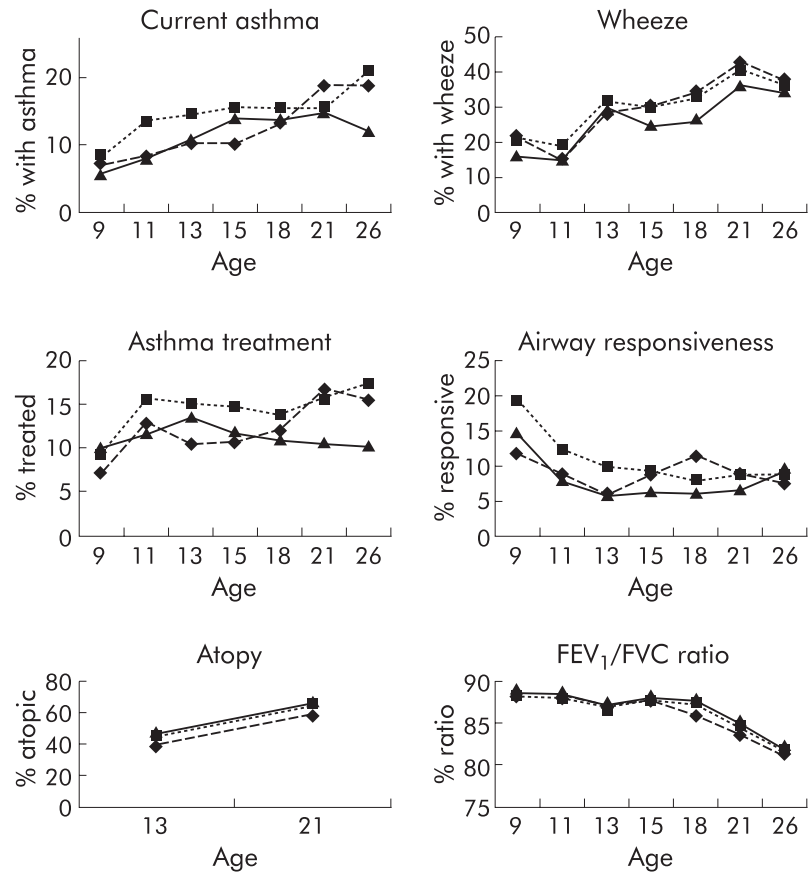

Figure 1 Prevalence of asthma, wheeze, asthma treatment, airway responsiveness, atopy, and spirometric values in high (mean Elley Irving score $\leqslant 2, \boldsymbol{\Delta}$ ), medium (mean score 2-4, $\boldsymbol{\square}$ ) and low (mean score $\geqslant 4-6, \bullet$ ) childhood socioeconomic status (SES) groups. smoking (data not shown). The $\mathrm{FEV}_{\mathrm{l}} / \mathrm{FVC}$ ratio tended to be lower in those with lower educational achievement $(p=0.026)$ and lower SES $(p=0.071)$, but these were not significant in the fully adjusted analyses $(p=0.13$ and 0.16 , respectively).

\section{Impact of asthma on adult SES and educational achievement}

There were no significant associations between a diagnosis of asthma in childhood and the educational achievement or adult SES of the study member at age 26 , even after adjusting for childhood SES.

\section{DISCUSSION}

This study found no convincing evidence of an association between childhood SES and asthma at any age from childhood to early adulthood. The findings were consistent whether we used parental occupation or parental income as the measure of childhood SES. Furthermore, adult SES had no influence on adult asthma, and a diagnosis of asthma in childhood had no impact on educational achievement or adult SES. Our findings with regard to asthma contrast with those for other health problems in this cohort in which significantly worse adult health occurred in those who grew up in a low SES background. ${ }^{46}$

There was a significant trend to increased atopy with higher childhood SES. This was not statistically significant after adjusting for potential confounding factors, but is consistent with the findings of other studies. ${ }^{11}$ We did not find any significant association between serum IgE and SES.

This study addresses some of the problems which limit the interpretation of previous studies. Firstly, we have prospectively collected data throughout childhood into early adulthood, allowing a search for consistent associations between SES and asthma at different ages. Secondly, objective measures of lung function and airway responsiveness were performed as well as subjective measures of asthma such as symptoms, doctor diagnosis, and treatment. We can therefore discount apparent differences in the prevalence of asthma due to selective reporting of symptoms, differences in diagnostic practice, or access to care. Thirdly, detailed information was available on known and potential confounders such as smoking during pregnancy, parental asthma, parental smoking (indicating likely exposure to environmental tobacco smoke), birth order, and breast feeding.

Although we have identified no relationship between SES and asthma from childhood to early adulthood, this does not preclude an association during later life. There was a trend to a reduced prevalence of asthma and less asthma treatment in those from advantaged socioeconomic backgrounds by age 26 (fig 1). However, this trend was not apparent for wheeze, airway responsiveness, or lung function and was in the opposite direction to the trend observed for atopy.

The generalisability of our findings to other populations is unclear. In common with any study of social conditions and health, the findings may not apply to societies in which social conditions differ markedly. Although the Dunedin cohort represents the entire socioeconomic spectrum of New Zealand, the range and nature of the socioeconomic disparities may be less or greater in other countries. In addition, issues relating asthma to SES may differ across countries. For example, poor housing in the USA may expose children to high levels of cockroach allergen. In this cohort cockroach allergy was less common than allergy to house dust mite (unpublished). Exposure to house dust mite is likely to be universal in a city such as Dunedin. ${ }^{47}$ Nevertheless, we believe that this study is the most comprehensive examination of the relationship between asthma and socioeconomic conditions to date. Data from 
Table 1 Odds ratios, coefficients and $95 \%$ confidence intervals from cross sectional time series analyses of asthma, wheeze, asthma treatment, time off school/work due to asthma, bronchial responsiveness, atopy, $\mathrm{FEV}_{1} / \mathrm{FVC}$ ratio, and log serum IgE on childhood socioeconomic status (SES; 1 = professional, $6=$ manual labourer)

\begin{tabular}{|c|c|c|c|c|c|c|}
\hline & \multicolumn{3}{|c|}{ Adjusted for sex only } & \multicolumn{3}{|c|}{ Fully adjusted } \\
\hline & $\mathbf{n}$ & OR & $95 \% \mathrm{Cl}$ & $\mathbf{n}$ & OR & $95 \% \mathrm{Cl}$ \\
\hline Current asthma & 6104 & 1.07 & 0.94 to 1.21 & 4939 & 1.07 & 0.92 to 1.25 \\
\hline Wheeze & 6096 & 1.04 & 0.96 to 1.13 & 4937 & 1.05 & 0.96 to 1.16 \\
\hline Asthma treatment & 6099 & 1.05 & 0.92 to 1.19 & 4936 & 1.05 & 0.90 to 1.22 \\
\hline $\begin{array}{l}\text { Time off school/ } \\
\text { work }\end{array}$ & 5278 & 1.08 & 0.93 to 1.26 & 4220 & 1.11 & 0.94 to 1.30 \\
\hline $\begin{array}{l}\text { Bronchial } \\
\text { response }^{*}\end{array}$ & 5656 & 1.07 & 0.94 to 1.21 & 4632 & 1.03 & 0.88 to 1.20 \\
\hline \multirow[t]{2}{*}{ Atopy } & 1593 & $0.90^{* *}$ & 0.80 to 1.00 & 1299 & 0.89 & 0.78 to 1.02 \\
\hline & n & Coefficient & $95 \% \mathrm{Cl}$ & $\mathbf{n}$ & Coefficient & $95 \% \mathrm{Cl}$ \\
\hline $\begin{array}{l}\mathrm{FEV}_{1} / \mathrm{FVC} \text { ratio } \\
\text { Log lgE }\end{array}$ & $\begin{array}{l}5860 \\
1350\end{array}$ & $\begin{array}{l}-0.13 \\
0.03\end{array}$ & $\begin{array}{l}-0.46 \text { to } 0.20 \\
-0.06 \text { to } 0.12\end{array}$ & $\begin{array}{l}4792 \\
1095\end{array}$ & $\begin{array}{l}-0.03 \\
0.01\end{array}$ & $\begin{array}{l}-0.42 \text { to } 0.37 \\
-0.10 \text { to } 0.11\end{array}$ \\
\hline
\end{tabular}

$\mathrm{n}=$ number of observations in each analysis (several observations made for each subject at different ages); $\mathrm{OR}=$ odds ratio (change in odds of the outcome for each point change in the SES scale); coefficient=change in prevalence of outcome for each point change in the SES scale; $\mathrm{FEV}_{1}=$ forced expiratory volume in 1 second; FVC $=$ forced vital capacity.

*Bronchial responsiveness means a response to methacholine or salbutamol as defined in the text. Fully adjusted figures are adjusted for sex, breast feeding, parental asthma, parental smoking, birth order, and smoking during pregnancy.

${ }^{* *} p<0.05$.

surveys in other countries should be interpreted in the light of the methodological issues that we have raised.

\section{ACKNOWLEDGEMENTS}

We are grateful to the study members and their parents for their continued support. We also thank Air New Zealand and Dr Phil A Silva, the study founder.

\section{Authors' affiliations \\ R J Hancox, B J Milne, R Poulton, Dunedin Multidisciplinary Health and Development Research Unit, Dunedin School of Medicine, University of} Otago, Dunedin, New Zealand

D R Taylor, J O Cowan, E M Flannery, C R McLachlan, Department of Medical and Surgical Sciences, Dunedin School of Medicine, University of Otago, Dunedin, New Zealand

J M Greene, M R Sears, Firestone Institute for Respiratory Health, Department of Medicine, McMaster University, Hamilton, Ontario, Canada

G P Herbison, Department of Preventive and Social Medicine, Dunedin School of Medicine, University of Otago, Dunedin, New Zealand

The Dunedin Multidisciplinary Health and Development Research Unit is funded by the Health Research Council of New Zealand. The respiratory section of the study was funded by the Health Research Council, the Otago Medical Research Foundation, the New Zealand Lottery Grants Board, and the Asthma Foundation of New Zealand.

\section{REFERENCES}

1 Burney PG, Chinn S, Rona RJ. Has the prevalence of asthma increased in children? Evidence from the national study of health and growth 1973-86. BMJ 1990;300:1306-10.

2 Robertson CF, Heycock E, Bishop J, et al. Prevalence of asthma in Melbourne schoolchildren: changes over 26 years. BMJ 1991;302:1116-8.

3 Goren Al, Hellmann S. Has the prevalence of asthma increased in children? Evidence from a long term study in Israel. J Epidemiol Community Health 1997;51:227-32.

4 Rona RJ, Chinn S, Burney PG. Trends in the prevalence of asthma in Scottish and English primary school children 1982-92. Thorax 1995;50:992-3.

5 Peat JK, van den Berg RH, Green WF, et al. Changing prevalence of asthma in Australian children. BMJ 1994;308:1591-6.

6 Anderson HR, Butland BK, Strachan DP. Trends in prevalence and severity of childhood asthma. BMJ 1994;308:1600-4.

7 Strachan DP. Time trends in asthma and allergy: ten questions, fewer answers. Clin Exp Allergy 1995;25:791-4.

8 Stewart AW, Mitchell EA, Pearce N, et al. The relationship of per capita gross national product to the prevalence of symptoms of asthma and other atopic diseases in children (ISAAC). Int J Epidemiol 2001;30:173-9.
9 Worldwide variation in prevalence of symptoms of asthma, allergic rhinoconjunctivitis, and atopic eczema: ISAAC. The International Study of Asthma and Allergies in Childhood (ISAAC) Steering Committee. Lancet 1998;351:1225-32.

10 von Mutius E, Martinez FD, Fritzsch $C$, et al. Prevalence of asthma and atopy in two areas of West and East Germany. Am J Respir Crit Care Med 1994; 149:358-64

11 Strachan DP. Family size, infection and atopy: the first decade of the "hygiene hypothesis". Thorax 2000;55(Suppl 1):S2-10.

12 Mielck A, Reitmeir P, Wist M. Severity of childhood asthma by socioeconomic status. Int J Epidemiol 1996;25:388-93.

13 Rona RJ. Asthma and poverty. Thorax 2000;55:239-44.

14 Hamman RF, Halil T, Holland WW. Asthma in schoolchildren. Demographic associations and peak expiratory flow rates compared in children with bronchitis. Br J Prev Soc Med 1975;29:228-38.

15 Lewis S, Richards D, Bynner J, et al. Prospective study of risk factors for early and persistent wheezing in childhood. Eur Respir J 1995;8:349-56.

16 Peckham C, Butler N. A national study of asthma in childhood. J Epidemiol Community Health 1978;32:79-85.

17 Chen $Y$, Tang $M$, Krewski D, et al. Relationship between asthma prevalence and income among Canadians. JAMA 2001;286:919-20.

18 Duran-Tauleria E, Rona RJ. Geographical and socioeconomic variation in the prevalence of asthma symptoms in English and Scottish children. Thorax 1999:54:476-81.

19 Eachus J, Williams M, Chan P, et al. Deprivation and cause specific morbidity: evidence from the Somerset and Avon survey of health. BMJ 1996;312:287-92.

20 Halfon N, Newacheck PW. Childhood asthma and poverty: differential impacts and utilization of health services. Pediatrics 1993;91:56-61.

21 Weitzman M, Gortmaker S, Sobol A. Racial, social, and environmental risks for childhood asthma. Am J Dis Child 1990;144:1189-94.

22 Gergen PJ, Mullally DI, Evans R 3rd. National survey of prevalence of asthma among children in the United States, 1976 to 1980. Pediatrics 1988;81:1-7.

23 Goodman E. The role of socioeconomic status gradients in explaining differences in US adolescents' health. Am J Public Health 1999;89:1522-8.

24 SIDRIA (Italian Studies on Respiratory Disorders in Childhood and the Environment). Asthma and respiratory symptoms in 6-7 yr old Italian children: gender, latitude, urbanization and socioeconomic factors. Eur Respir J 1997; 10:1780-6.

25 Mitchell EA, Stewart AW, Pattemore PK, et al. Socioeconomic status in childhood asthma. Int J Epidemiol 1989; 18:888-90.

26 Herrstrom P, Hogstedt B. Allergic diseases, dental health, and socioeconomic situation of Swedish teenagers. Allergy, dental health, and social situation. Scand J Prim Health Care 1994;12:57-61.

27 Leeder SR, Corkhill RT, Irwig LM, et al. Influence of family factors on asthma and wheezing during the first five years of life. Br J Prev Soc Med 1976;30:213-8

28 Poyser MA, Nelson H, Ehrlich Rl, et al. Socioeconomic deprivation and asthma prevalence and severity in young adolescents. Eur Respir J 2002; 19:892-8.

29 Schenker MB, Samet JM, Speizer FE. Risk factors for childhood respiratory disease. The effect of host factors and home environmental exposures. Am Rev Respir Dis 1983;128:1038-43. 
30 Sarpong SB, Hamilton RG, Eggleston PA, et al. Socioeconomic status and race as risk factors for cockroach allergen exposure and sensitization in children with asthma. J Allergy Clin Immunol 1996;97:1393-401.

31 Kitch BT, Chew G, Burge HA, et al. Socioeconomic predictors of high allergen levels in homes in the greater Boston area. Environ Health Perspect 2000;108:301-7.

32 Lewis SA, Weiss ST, Platts-Mills TA, et al. Association of specific allergen sensitization with socioeconomic factors and allergic disease in a population of Boston women. J Allergy Clin Immunol 2001;107:615-22.

33 Leaderer BP, Belanger K, Triche E, et al. Dust mite, cockroach, cat, and dog allergen concentrations in homes of asthmatic children in the northerstern United States: impact of socioeconomic factors and population density. Environ Health Perspect 2002;110:419-25.

34 Silva PA, Stanton WR. From child to adult: the Dunedin Multidisciplinary Health and Development Study. Auckland: Oxford University Press, 1996.

35 Elley WB, Irving JC. The Elley-Irving socio-economic index 1981 census revision. NZ J Educ Stud 1985;29:115-28.

36 Jones DT, Sears MR, Holdaway MD, et al. Childhood asthma in New Zealand. $\mathrm{Br} J$ Dis Chest 1987;81:332-40.

37 Burney P, Chinn S. Developing a new questionnaire for measuring the prevalence and distribution of asthma. Chest 1987;91:79S-83S.

38 Ferris BG. Epidemiology Standardization Project (American Thoracic Society). Am Rev Respir Dis 1978;118:1-120.
39 Chai H, Farr RS, Froehlich LA, et al. Standardization of bronchial inhalation challenge procedures. J Allergy Clin Immunol 1975;56:323-7.

40 Sears MR, Jones DT, Holdaway MD, et al. Prevalence of bronchial reactivity to inhaled methacholine in New Zealand children. Thorax 1986;41:283-9.

41 Sears MR, Herbison GP, Holdaway MD, et al. The relative risks of sensitivity to grass pollen, house dust mite and cat dander in the development of childhood asthma. Clin Exp Allergy 1989;19:419-24.

42 Sears MR, Burrows B, Flannery EM, et al. Relation between airway responsiveness and serum lgE in children with asthma and in apparently normal children. N Engl J Med 1991;325:1067-71.

43 Sears MR, Jones DT, Silva PA, et al. Asthma in seven year old children: a report from the Dunedin Multidisciplinary Child Development Study. NZ Med J 1982;95:533-6.

44 Sears MR, Greene JM, Willan AR, et al. Long-term relation between breastfeeding and development of atopy and asthma in children and young adults: a longitudinal study. Lancet 2002;360:901-7.

45 Sears MR, Taylor DR, Poulton R. Breastfeeding and asthma: appraising the controversy-a rebuttal. Pediatr Pulmonol 2003;36:366-8.

46 Poulton R, Caspi A, Milne BJ, et al. Association between children's experience of socioeconomic disadvantage and adult health: a life-course study. Lancet 2002;360:1640-5

47 McRae WM, Flannery EM, Cowan JO, et al. House dust mite allergen levels in university student accommodation in Dunedin. NZ Med J 2002;115:U30.

\section{LUNG ALERT}

\section{Abnormalities of fatty acid metabolism in CF}

$\Delta$ Freedman SD, Blanco PG, Zaman MM, et al. Association of cystic fibrosis with abnormalities in fatty acid metabolism. N Engl J Med 2004;350:560-9

$\mathrm{T}$

his study found low tissue levels of the fatty acid docosahexaenoic acid (DA) and a raised ratio of arachidonic acid (AA) to DA in patients with cystic fibrosis (CF) compared with healthy controls in nasal and rectal biopsy specimens $(\mathrm{p}<0.001$ and $p=0.009$ for the ratios, respectively). In cells from nasal scrapings the AA:DA ratio was also significantly higher in subjects with CF than in controls $(\mathrm{p}<0.001)$, with CF carriers showing intermediate levels between the two $(\mathrm{p}<0.001)$. Intermediate levels similar to $\mathrm{CF}$ carriers were observed in patients with asthma or acute upper respiratory tract infections (UTRI), but lower levels were observed in those with inflammatory bowel disease. The findings in CF were independent of pancreatic sufficiency status. No difference between plasma levels of two essential amino acids, linoleic acid and eicosatrienoic acid, or AA were noted between CF patients, carriers, and healthy controls. The authors suggest that the imbalance may be a result of cystic fibrosis transmembrane conductance regulator gene expression in these tissues rather than a consequence of malabsorption, although "intermediate" levels in those with asthma or an URTI suggest that other factors are involved. Fatty acids such as DA can be converted into potent anti-inflammatory mediators and the low levels observed in this study may lead to the excessive inflammatory response observed in $\mathrm{CF}$.

This study confirms a tissue abnormality of fatty acid metabolism in CF, previously only demonstrated in CF knockout mice. Correction of this imbalance could be a potential treatment target in $\mathrm{CF}$.

S Bailey

Clinical Fellow, The Manchester Adult Cystic Fibrosis Centre, Wythenshawe Hospital, Manchester, UK Simon.Bailey@smuht.nwest.nhs.uk 